\title{
Thermal radiation impact on boundary layer dissipative flow of magneto-nanofluid over an exponentially stretching sheet
}

\author{
Syed M. Hussain ${ }^{1}$, Rohit Sharma ${ }^{2}$, Gauri S. Seth ${ }^{3 *}$, Manas R. Mishra ${ }^{1}$ \\ ${ }^{1}$ Department of Mathematics, OP Jindal University, Raigarh, 496109, India \\ ${ }^{2}$ Department of Mathematics, Gitam, Bangaluru, 560066, India \\ ${ }^{3}$ Department of Applied Mathematics, Indian Institute of Technology (ISM), Dhanbad, 826004, India
}

Corresponding Author Email: gsseth_ism@yahoo.com

https://doi.org/10.18280/ijht.360402

Received: 29 August 2018

Accepted: 30 October 2018

\section{Keywords:}

magneto-nanofluid, thermal radiation, heat absorption, viscous and joule dissipations, Navier's velocity slip

\begin{abstract}
The impact of thermal radiation on viscous dissipative boundary layer flow of heat absorbing magneto-nanofluid over a permeable exponentially stretching sheet with Navier's velocity and thermal slips has been analyzed. The prevailing mathematical equations are changed to nonlinear ordinary differential equations using the appropriate similarity variables and then the equations are numerically solved by Runge-Kutta scheme of fourth order together with the shooting technique. Three kinds of water based nanofluids having aluminum oxide, copper and titanium oxide as nanoparticles are considered for this investigation. The consequence of relevant flow parameters on nanofluid velocity, temperature distribution, wall velocity gradient and local Nusselt number are displayed by means of various graphs. In addition, analysis of quadratic regression estimation on the numerical data of coefficient of skin friction and local Nusselt number has been presented to verify the relationship among the controlling physical parameters and transfer rate parameters. Our result reveals that the velocity and temperature distribution profiles are lower for $\mathrm{Cu}$-water nanofluid followed by $\mathrm{Al}_{2} \mathrm{O}_{3}$ and $\mathrm{TiO}_{2}$ water base nanofluids in the regime of boundary layer. The thermal radiation and viscous dissipation have tendency to augment the $\mathrm{Cu}$-water temperature over the stretching sheet.
\end{abstract}

\section{INTRODUCTION}

Now days, the demand for high-performance and proficient coolants in numerous industrial processes related to automobiles, metallurgy, power production, electronics, medical, etc., encouraged the several researchers towards nanofluids. The traditional fluids such as water, polymer solutions, ethylene glycol, oils and other lubricants have poor characteristics of heat transfer as these fluids have limited thermal conductivity. To augment the thermal conductivity of these traditional fluids, the researchers switched towards the artificial fluids termed as nanofluids by submerging the micro/nano sized metal particles into the traditional fluids (base fluids). Foremost, Choi [1] proved that the thermal conductivity of traditional fluids can be radically augmented by suspending the macro/nano sized particles of metal uniformly into the traditional fluids. This concept incited many researchers towards nanofluids, and numerous investigations were carried out to analyze the applications and thermo-physical properties of nanofluids [2-12]. Further, the experimental or theoretical analysis of magnetohydrodynamic (MHD) flow over the permeable and non-permeable stretching sheets has been vigorously done by several researchers owing to its enormous relevance in modern industry such as in heat storage systems, oil recovery techniques, production of emollient, fiber and wire coating, elastic polymer substance, chemical equipment processing, thermal insulations, manufacturing of uniform and long metal parts, etc. It is noted that the pioneering work on the hydromagnetic flow of fluid owing to deformation of plane surface was performed by Pavlov [13]. Further, this investigation was explored by Chakrabarti and Gupta [14] taking into the consideration of temperature distribution, which may find the applications in various technology and industry such as polymer technology and in metallurgical process that engross cooling of the continuous strips. Makinde et al. [15] explored the impact of buoyancy force, magnetic field and Brownian motion on the stagnation point nanofluid flow over the stretched sheet. Moreover, Hayat et al. [16] discussed the magneto three dimensional fluid flow permeated by an exponentially stretched sheet. Most recently, Khan [17] obtained the series solution to explore the impact of magnetic field and other various relevant parameters on the visco-elastic flow of fluid over the shrinking or stretching sheet.

The consequence of heat source and/or sink on the laminar boundary layer fluid flow over a permeable stretched sheet has been accounted by many researchers owing to its strong consequences on the heat transfer characteristics. Following this, similarity solutions of boundary layer fluid flow driven by the stretched sheet considering heat source/sink is obtained by Elbashbeshy [18], which reveals that the suction can act as a medium for the cooling of moving continuous surface. Moreover, Elbashbeshy and Bazid [19] extended this study considering the unsteady boundary layer flow. Most recently, Ibrahim et al. [20] studied the impact of CattaneoChristov heat flux on the flow of UCM fluid past a melting surface under the influence of exponentially decaying heat 
source/sink. Makinde et al. [21-22] discussed the magnetohydrodynamic mixed convective nanofluid flow over a permeable stretched sheet. It may be noted that many industrial processes like designing of furnace, solar power technology, production of glass, electrical power generation, propulsion devices for missiles and aircraft, etc. occurs at typically high temperature wherein the role of thermal radiation is noteworthy for surface heat transfer. Moreover, in the current circumstances, at a rapid pace the diminution of existing sources of conventional energy has drawn the attention to switch in the direction of renewable and sustainable energy sources for many industrial applications. The main source of renewable energy is the solar energy and the thermal radiation may act crucial part to convert the solar energy to the suitable form for the various industrial and scientific applications. For this reason, countless researchers have explored the consequences of radiative heat transfer on the boundary layer fluid flow over the plate/stretched sheet [23-26].

It is observed that the impact of viscous dissipation has not been accounted in aforementioned studies. Even though the viscous dissipation impact is presumed to be limited, but it's consequences in food processing, polymer manufacturing, instrumentations, lubrications etc. become significant because it amends the temperature distribution characteristics by acting like a typical energy source which tends to influence the rate of heat transfer. Some relevant investigations considering the viscous dissipation permeated by the stretched sheet are reported [27-30]. In addition to viscous dissipation's behavior, the Joule dissipation behaves like volumetric heat source in the hydromagnetic flows. In particular, the combined Joule and viscous dissipations influence are important in the heat treated materials confined among the nourished and wind-up rolls. Due to this reason, many researchers including of Anjali Devi and Ganga [31], Pal [32], Seth and Singh [33] and Seth et al. [34-35], etc. considered the combined influence of viscous and Joule dissipations. Most recently, Seth et al. [36] discussed the impact of Joule dissipation on the magneto-Casson fluid flow considering thin film over the horizontal stretched sheet.

However, in above discussed studies, the analytical/numerical solutions are analyzed assuming the noslip boundary condition. But there are various physical situations like low pressure flows, nano/micro-scale flows etc. in which this boundary condition is not applicable. The phenomenon of non-adherence of fluids to the solid boundary is noticed under certain situations and is recognized as velocity slip. In the case of coated surface viz. resist adhesion and Teflon, no-slip condition is converted to Navier's partial slip in which the velocity slip is directly proportional to surface property and local shear stress. Following this, Mukopadhyay and Gorla [37] investigated significance of partial slip and radiative heat transfer on the boundary layer flow induced by porous exponentially stretched sheet. Moreover, Mukhopadhyay [38] discussed the impacts of partial slip on hydromagnetic and thermal radiative boundary layer flow considering suction/blowing over an exponentially stretched sheet. Sharma et al. [39] obtained the numerical solution of partial slip boundary layer and radiative flow of nanofluid with heat transfer over stretched sheet and discussed the influence of flow parameters in details.

In present study, our intent is to examine the impact of thermal radiation on viscous dissipative boundary layer flow of magneto-nanofluid with heat absorption over a permeable exponentially stretching sheet considering Navier's velocity and thermal slips into account. To the best of our information, no one has attempted this problem which may find the applications in polymer technology and in metallurgical process that engross cooling of the continuous strips.

\section{MATHEMATICAL ANALYSIS}

\subsection{Mathematical formulation of problem}

The steady two-dimensional viscous dissipative boundary layer flow of an optically thick heat radiative, electrically conducting and incompressible magneto-nanofluid over a permeable exponentially stretched sheet is considered. The stretching sheet is aligned with $x$-axis whereas $y$-axis is taken in normal direction and flow of fluid being restricted to $y>$ 0 . The fluid is infused over the permeable exponentially stretched sheet owing to the velocity $\lambda_{1}(x)$. The nanofluid is permeated by uniform magnetic field $B_{0}$ exerted normal to the permeable stretched sheet. At the surface of stretched, the temperature is presumed to be constant given by $\bar{T}_{\varepsilon}$ while those of ambient nanofluid is considered as $\bar{T}_{\infty}$. The schematic representation of problem is displayed in Figure 1. Three kinds of water based nanofluids comprising of aluminum oxide, copper and titanium oxide as nanoparticles and its influence are taken into account. Further, both nanoparticles and base fluid are in thermal equilibrium and no slip mechanism occurs between them. Moreover, very small magnetic Reynolds number is considered to neglect induced magnetic field. The thermo-physical characteristics of water and the considered nanoparticles are shown in Table 1 .

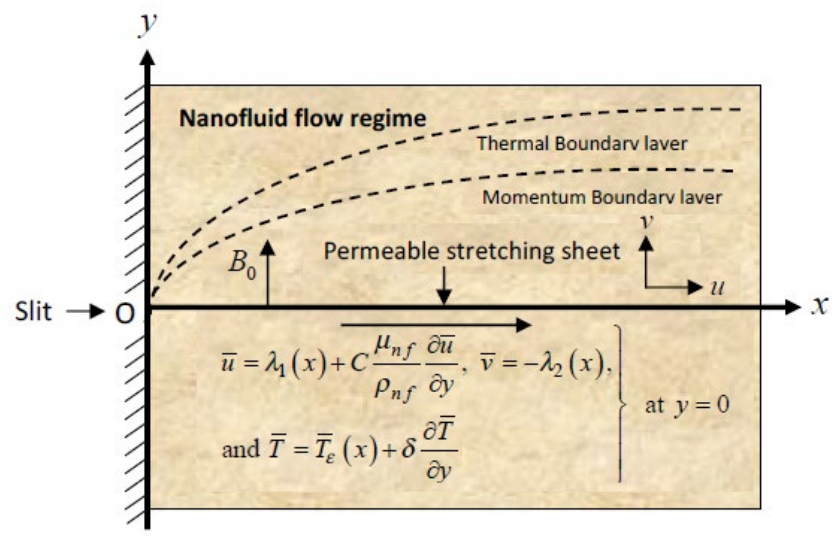

Figure 1. The schematic representation of problem

Table 1. Thermo physical characteristics of base fluid and nanoparticles [40]

\begin{tabular}{lcccc}
\hline & $\mathbf{T i O}_{2}$ & $\mathbf{A l}_{2} \mathbf{O}_{3}$ & $\mathbf{C u}$ & Water \\
\hline$\rho\left(\mathrm{kg} / \mathrm{m}^{3}\right)$ & 4250 & 3970 & 8933 & 997.1 \\
\hline$c_{p}(\mathrm{~J} / \mathrm{kg} \mathrm{K})$ & 686.2 & 765 & 385 & 4179 \\
\hline$k(\mathrm{~W} / \mathrm{mK})$ & 8.9538 & 40 & 401 & 0.613 \\
\hline$\phi$ & 0.20 & 0.15 & 0.05 & 0.00 \\
\hline$\sigma(\Omega \cdot \mathrm{m})^{-1}$ & $1 \times 10^{-12}$ & $1 \times 10^{-10}$ & $59.6 \times 10^{6}$ & 0.05 \\
\hline
\end{tabular}

Owing to aforesaid assumptions, the governing mathematical equations of the problem are given by 
$\frac{\partial \bar{u}}{\partial x}+\frac{\partial \bar{v}}{\partial y}=0$

$\bar{u} \frac{\partial \bar{u}}{\partial x}+\bar{v} \frac{\partial \bar{u}}{\partial y}=\frac{\mu_{n f}}{\rho_{n f}} \frac{\partial^{2} \bar{u}}{\partial y^{2}}-\frac{\sigma_{n f} B_{0}^{2}}{\rho_{n f}} \bar{u}$,

$\bar{u} \frac{\partial \bar{T}}{\partial x}+\bar{v} \frac{\partial \bar{T}}{\partial y}=\frac{k_{n f}}{\left(\rho c_{p}\right)_{n f}} \frac{\partial^{2} \bar{T}}{\partial y^{2}}+\frac{\mu_{n f}}{\left(\rho c_{p}\right)_{n f}}\left(\frac{\partial \bar{u}}{\partial y}\right)^{2}$

$-\frac{1}{\left(\rho c_{p}\right)_{n f}}\left\{\frac{\partial q_{r}}{\partial y}-\sigma_{n f} B_{0}^{2} \bar{u}^{2}+Q_{0}\left(\bar{T}-\bar{T}_{\infty}\right)\right\}$.

As per the assumptions, the allied boundary conditions are presented by

$\left.\begin{array}{l}\bar{u}=\lambda_{1}(x)+C \frac{\mu_{n f}}{\rho_{n f}} \frac{\partial \bar{u}}{\partial y}, \bar{v}=-\lambda_{2}(x), \\ \bar{T}=\bar{T}_{\varepsilon}(x)+\delta \frac{\partial \bar{T}}{\partial y}\end{array}\right\}$ at $y=0$,

$\bar{u} \rightarrow 0, \bar{T} \rightarrow \bar{T}_{\infty}$ as $y \rightarrow \infty$

where $\lambda_{1}(x)=\lambda_{0} e^{x / L}$ is the velocity of stretched sheet, $\bar{T}_{\varepsilon}(x)=\left(\bar{T}_{0}-\bar{T}_{\infty}\right) e^{\delta_{0} x / 2 L}+\bar{T}_{\infty}$ is exponential nanofluid temperature distribution in the sheet, $\lambda_{0}$ and $\bar{T}_{0}$ are the velocity reference and temperature respectively, $\delta_{0}$ is the temperature distribution parameter within the stretched sheet, $C=C_{1} e^{-x / 2 L}$ is used for velocity slip factor wherein $C_{1}$ represents the initial velocity slip value, $\delta=\delta_{1} e^{-x / 2 L}$ signifies the thermal slip factor in which $\delta_{1}$ shows the initial thermal slip factor. Both velocity and thermal slip factors change along with the variable $x$. Meanwhile, no-slip occurs for $C=\delta=0$. Here $\lambda_{2}(x)=v_{0} e^{x / 2 L}$ indicates the suction/blowing velocity and $v_{0}$ is the suction/blowing velocity initial strength.

The expressions of $\rho_{n f}, \sigma_{n f},\left(\rho c_{p}\right)_{n f}$ and $\mu_{n f}$ for the nanofluid are defined [41-42] as

$$
\begin{aligned}
& \rho_{n f}=\rho_{f}\left\{(1-\phi)+\phi \frac{\rho_{s}}{\rho_{f}}\right\}, \sigma=\frac{\sigma_{s}}{\sigma_{f}}, \\
& \sigma_{n f}=\sigma_{f}\left[\frac{3(\sigma-1) \phi}{(\sigma+2)-(\sigma-1) \phi}+1\right], \\
& \left(\rho c_{p}\right)_{n f}=\left(\rho c_{p}\right)_{f}\left\{(1-\phi)+\phi \frac{\left(\rho c_{p}\right)_{s}}{\left(\rho c_{p}\right)_{f}}\right\}, \\
& \mu_{n f}=\mu_{f}(1-\phi)^{-5 / 2} .
\end{aligned}
$$

It may be noted that the abovementioned expressions (5) are constrained to spherical nanoparticles while it is not applicable for the nanoparticles having the other shape [40]. Further, for the nanofluid comprising of spherical shape nanoparticles the effective thermal conductivity $k_{n f}$ is given as $k_{n f} k_{f}^{-1}=\left\{\frac{k_{s}-2\left(k_{f}-k_{s}\right) \phi+2 k_{f}}{k_{s}+\left(k_{f}-k_{s}\right) \phi+2 k_{f}}\right\}$,

where $k_{f}$ and $k_{s}, k_{f}$ and $k_{s}$ are, respectively, the thermal conductivities of water and nanoparticles.

The Rosseland approximation is considered for optically thick radiative fluid [43] to express the radiative heat flux $q_{r}$ in the following form

$q_{r}=-\frac{4 \sigma^{*}}{3 k^{*}} \frac{\partial \bar{T}^{4}}{\partial y}$.

Moreover, $\bar{T}^{4}$ is linearized by expanding it about the free stream temperature $\bar{T}_{\infty}$ using the Taylor's series, which is represented below after neglecting the higher order terms

$\bar{T}^{4} \cong 4 \bar{T}_{\infty}^{3} \bar{T}-3 \bar{T}_{\infty}^{4}$.

Now using (7) and (8) in equation (3), we get

$$
\begin{aligned}
& \bar{u} \frac{\partial \bar{T}}{\partial x}+\bar{v} \frac{\partial \bar{T}}{\partial y}=\frac{1}{\left(\rho c_{p}\right)_{n f}}\left[k_{n f}+\frac{16 \sigma^{*} \bar{T}_{\infty}^{3}}{3 k^{*}}\right] \frac{\partial^{2} \bar{T}}{\partial y^{2}}+\frac{\mu_{n f}}{\left(\rho c_{p}\right)_{n f}}\left(\frac{\partial \bar{u}}{\partial y}\right)^{2} \\
& +\frac{1}{\left(\rho c_{p}\right)_{n f}}\left\{\sigma_{n f} B_{0}^{2} \bar{u}^{2}-Q_{0}\left(\bar{T}-\bar{T}_{\infty}\right)\right\} .
\end{aligned}
$$

\subsection{Numerical solution of problem}

For the physically reliable numerical solution of aforesaid problem, following similarity transforms [44] have been introduced

$$
\begin{aligned}
& \psi(x, y)=\sqrt{(2 R e)} e^{x / 2 L} v_{f} f(\eta), \eta(x, y)=\frac{y}{L} \sqrt{\frac{R e}{2}} e^{x / 2 L} \\
& \text { and } \bar{T}(x, y)=e^{\delta_{0} x / 2 L}\left(\bar{T}_{0}-\bar{T}_{\infty}\right) \theta(\eta)+\bar{T}_{\infty},
\end{aligned}
$$

where $v_{f}, R e, \psi, \eta$ and $\theta$ represent the fluid kinematic viscosity, Reynolds number, stream function, similarity variable and dimensionless form of nanofluid temperature respectively where $\psi$ (stream function) is defined by the following relations

$\bar{u}=\frac{\partial \psi}{\partial y}$ and $\bar{v}=-\frac{\partial \psi}{\partial x}$.

Now using equation (10) in (11), we get

$$
\left.\begin{array}{l}
\bar{u}=\frac{R e v_{f}}{L} e^{x / L} f^{\prime}(\eta) \text { and } \\
\bar{v}=-\frac{\sqrt{2 \operatorname{Re}} v_{f}}{2 L}\left[f(\eta)+\eta f^{\prime}(\eta)\right] e^{x / 2 L},
\end{array}\right\}
$$

where primes indicate the differentiation with respect to $\eta$.

The equations (10) and (11) transform the equations (2) and (9) into the set of non linear ordinary equations:

$$
\phi_{1} f^{\prime \prime \prime}+\phi_{2}\left(f^{\prime \prime} f-2 f^{\prime 2}\right)-2 \phi_{3} M e^{-X} f^{\prime}=0,
$$




$$
\begin{aligned}
\left(\frac{K_{1}+R}{\operatorname{Pr} \phi_{4}}\right) \theta^{\prime \prime}+f \theta^{\prime} & -\delta_{0} \theta f^{\prime}+E c\left(\phi_{1} e^{X} f^{\prime \prime 2}+2 \phi_{3} M f^{\prime 2}\right) e^{\left(2-\delta_{0}\right) X / 2} \\
& -\frac{2 \xi}{\phi_{4}} e^{-X} \theta=0
\end{aligned}
$$

with the associated boundary conditions in dimensionless forms as obtained from the equations (4a) and (4b) in the following form

$$
\begin{aligned}
& f^{\prime}=1+\lambda_{3} f^{\prime \prime}, f=S \text { and } \theta=1+\delta_{2} \theta^{\prime} \text { at } \eta=0, \\
& f^{\prime} \rightarrow 0 \text { and } \theta \rightarrow 0 \text { as } \eta \rightarrow \infty
\end{aligned}
$$

where $X=x L^{-1}$ is the dimensionless coordinate. The dimensionless parameters appearing in the equations (13)(15b) are

$$
\begin{aligned}
& M=\frac{\sigma_{f}\left(B_{0} L\right)^{2}}{\operatorname{Re} \mu_{f}}, \operatorname{Pr}=\frac{\left(\rho v c_{p}\right)_{f}}{k_{f}}, R=\frac{16 \sigma^{*} \bar{T}_{\infty}^{3}}{3 k^{*} k_{f}}, R e=\frac{\lambda_{0} L}{v_{f}}, \\
& E c=\frac{\lambda_{0}^{2}}{\left(c_{p}\right)_{f}\left(\bar{T}_{0}-\bar{T}_{\infty}\right)}, \xi=\frac{Q_{0} L^{2}}{\rho_{f} v_{f}\left(c_{p}\right)_{f} R e}, \lambda_{3}=\frac{C_{1} \mu_{n f}}{L \rho_{n f}} \sqrt{\frac{R e}{2}} \\
& \delta_{2}=\frac{\delta_{1}}{L} \sqrt{\frac{R e}{2}} \text { and } S=\frac{v_{0} L}{v_{f}} \sqrt{\frac{2}{R e}} .
\end{aligned}
$$

Also, we have

$$
\begin{aligned}
& \phi_{1}=\frac{1}{(1-\phi)^{2.5}}, \phi_{2}=\frac{1}{\rho_{f}}\left\{(1-\phi) \rho_{f}+\phi \rho_{s}\right\}, \\
& \left.\phi_{3}=\frac{(\sigma+2)+2(\sigma-1) \phi}{(\sigma+2)-(\sigma-1) \phi}, \phi_{4}=\left\{(1-\phi)+\phi \frac{\left(\rho c_{p}\right)_{s}}{\left(\rho c_{p}\right)_{f}}\right\}\right\} \\
& \text { and } K_{1}=\left\{\frac{k_{s}-2\left(k_{f}-k_{s}\right) \phi+2 k_{f}}{k_{s}+\left(k_{f}-k_{s}\right) \phi+2 k_{f}}\right\} .
\end{aligned}
$$

\subsection{Skin friction coefficient and local Nusselt number}

For the engineering interest, the skin friction coefficient $C f_{x}$ and local Nusselt number $N u_{x}$ are, respectively, given by

$$
C f_{x}=\tau_{w}\left\{\rho_{f} \lambda_{1}^{2}(x)\right\}^{-1} \text { and } N u_{x}=x q_{w}\left\{k_{f}\left(\bar{T}_{\varepsilon}-\bar{T}_{\infty}\right)\right\}^{-1}
$$

where $\quad \tau_{w}=\mu_{n f}(\partial u / \partial y)_{y=0} \quad$ and $q_{w}=-k_{n f}(\partial \bar{T} /$ $\partial y)_{y=0}+\left(q_{r}\right)_{y=0}$ are the wall shear stress and wall heat flux respectively. The non-dimensional form of local skin friction coefficient and local Nusselt numbers are represented as

$$
\left.\begin{array}{l}
C f_{x}=\phi_{1} \operatorname{Re}_{x}^{-1 / 2} \sqrt{2 X} f^{\prime \prime}(0) \text { and } \\
N u_{x}=-K_{1}\left\{(1+R) R e_{x}^{1 / 2}(X / 2)^{1 / 2}\right\} \theta^{\prime}(0),
\end{array}\right\}
$$

where $R e_{x}=x \lambda_{1}(x) / v_{f}$ is the local Reynolds number.

\section{IMPLEMENTATION OF NUMERICAL METHOD FOR THE SOLUTION}

The solution of equations reported in section 2.2 cannot be obtained analytically owing to the coupled nature of nonlinear equations. Therefore, the numerical solutions of these equations along with the associated boundary conditions are obtained using shooting technique in conjunction with Runge-Kutta method of fourth order. Foremost, the prevailing equations (13) and (14) are changed into the set of highly coupled form of five first order non linear differential equations. To solve these set of equations by Runge-Kutta scheme of fourth order, the initial values of $f^{\prime \prime}(0)$ and $\theta^{\prime}(0)$ are needed. So, the initial guess values for $f^{\prime \prime}(0)$ and $\theta^{\prime}(0)$ are obtained using shooting technique. Further, these initial guess values are corrected with the help of Secant method. During the numerical computation step size is considered as 0.001 and the value of $\eta=17$ is considered for the associated boundary condition 15(b). In order to achieve the precise results the entire process is repeated wherein the tolerance error is considered as $10^{-6}$.

\section{RESULTS AND DISCUSSION}

Extensive numerical computation is performed for the nanofluid velocity $f^{\prime}(\eta)$, nanofluid temperature $\theta(\eta)$, skin friction coefficient $C f_{x}$ and wall temperature gradients using Runge-Kutta method of fourth order along with the shooting scheme. The computed numerical results are presented to illustrate a parametric study enumerating impacts of pertinent flow parameters on the flow field. Three kinds of water based nanofluids having titanium oxide, alumina and copper as nanoparticles are chosen for this investigation. Throughout the study, dimensionless physical parameters are considered as $\quad X=1.5, a=2, M=0.2, \phi=0.05, S=0.1, \lambda_{3}=$ $0.3, \delta_{2}=0.1, E c=0.1, R=0.1, \xi=0.1$ and $\operatorname{Pr}=6.2$ (for base fluid) unless stated otherwise. The nanofluid velocity and temperature distribution profiles for the three kinds of nanofluids consisting of $\mathrm{Cu}, \mathrm{Al}_{2} \mathrm{O}_{3}, \mathrm{TiO}_{2}$ as nanoparticles and water as base fluid over the exponentially stretching sheet are displayed in Figures $2 \mathrm{a}$ and $2 \mathrm{~b}$. It is noticed that $\mathrm{Cu}$-water nanofluid has lower velocity and temperature profiles followed by $\mathrm{Al}_{2} \mathrm{O}_{3}$-water and $\mathrm{TiO}_{2}$-water nanofluids in the regime of boundary layer. Further, it is also noted that these profiles nearly overlap with each other away from the stretching sheet for the precise values of pertinent flow parameters. Figures $3 a$ and $3 b$ depict the significance of volume fraction of nanoparticle $\phi$ on the $\mathrm{Cu}$-water nanofluid velocity $f^{\prime}(\eta)$ and nanofluid temperature $\theta(\eta)$. These figures inferred that the velocity of nanofluid gets retarded while temperature is enhanced due to augmentation of numeric values of $\phi$. This is because of the fact that enhancement in volume fraction of nanoparticle leads to thermal conductivity reduction of nanofluid which results the boundary layer thickness to decrease and viscosity to enhance and in turn the nanofluid velocity gets reduced and fluid temperature gets enhanced. The consequences of magnetic parameter $M$ on the profiles of velocity and temperature for $\mathrm{Cu}$-water nanofluid are displayed in Figures $4 \mathrm{a}$ and $4 \mathrm{~b}$. It is revealed that the nanofluid velocity gets slow down whereas temperature of fluid is enhanced on augmenting $M$. This tendency of magnetic field is justified because it produces an opposing 
force (i.e. Lorentz force), which works in opposite direction to the fluid flow and metal nanoparticles and as a result fluid velocity is retarded and fluid temperature gets enhanced.

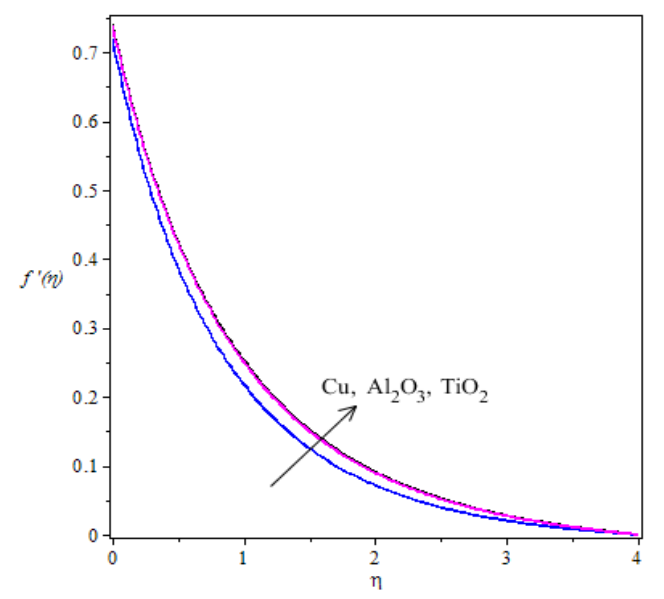

Figure 2a. Velocity profiles comparison for the different nanofluids

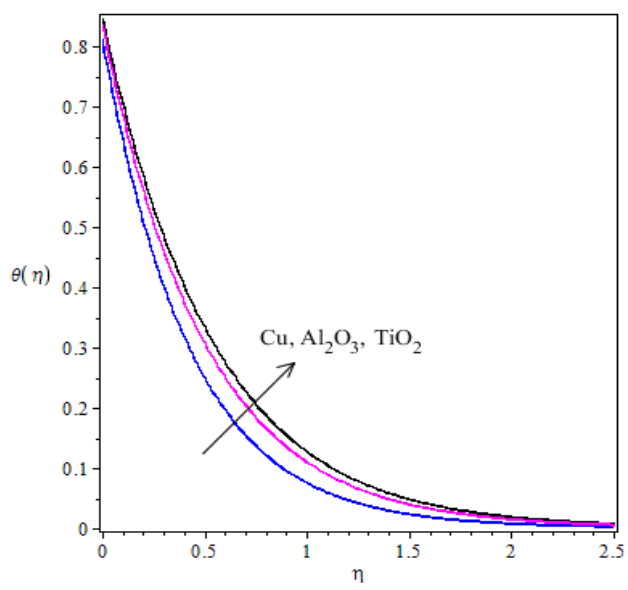

Figure 2b. Temperature distribution profiles comparison for the different nanofluids

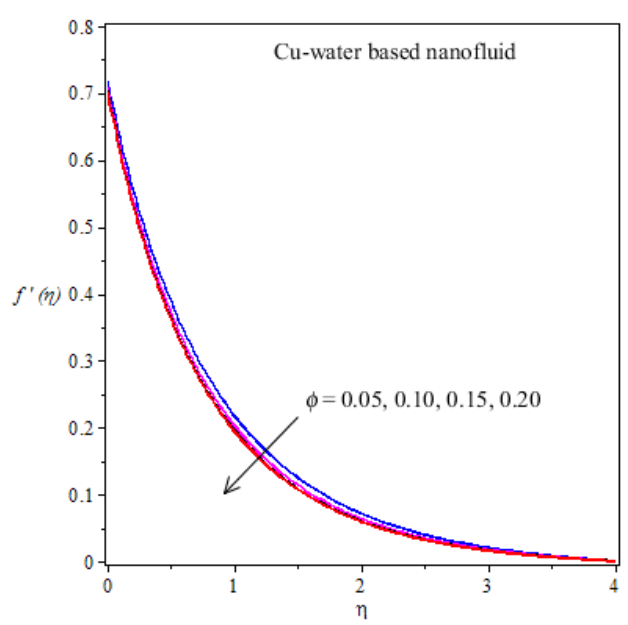

Figure 3a. Velocity profiles variation for varying values of $\phi$

Figures $5 \mathrm{a}$ and $5 \mathrm{~b}$ portray the influence of nondimensional coordinate $X$ on the $\mathrm{Cu}$-water nanofluid velocity profiles and temperature distribution. These figures illustrate that both the nanofluid velocity $f^{\prime}(\eta)$ and temperature $\theta(\eta)$ get enhanced on increasing $X$ which implies that the nondimensional coordinate $X$ has enhancing effect on both nanofluid velocity and temperature in the regime of boundary layer.

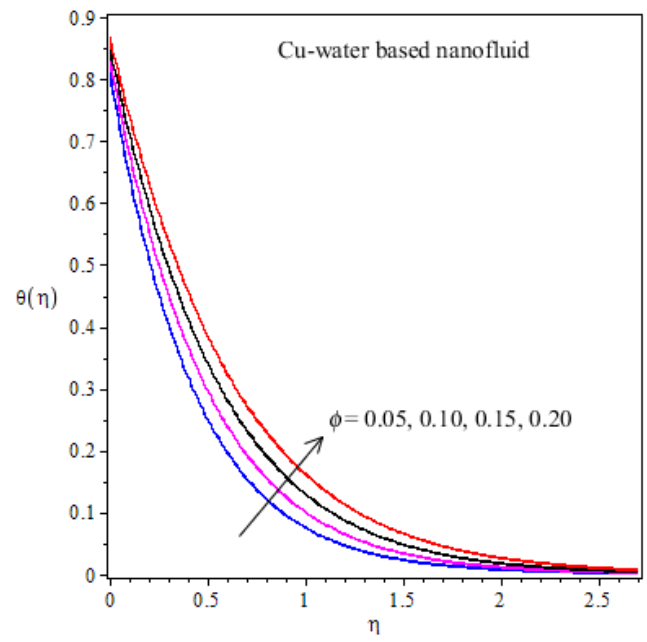

Figure 3b. Temperature profiles variation for varying values of $\phi$

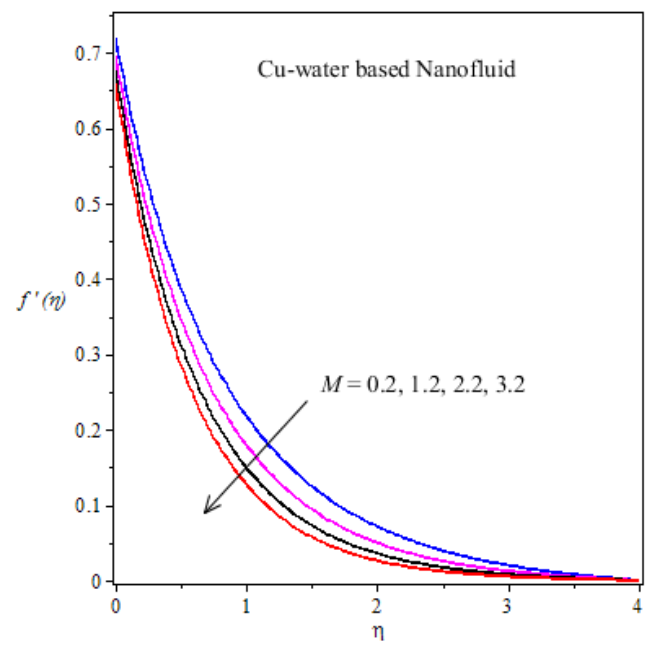

Figure 4a. Velocity profiles variation for varying values of $M$

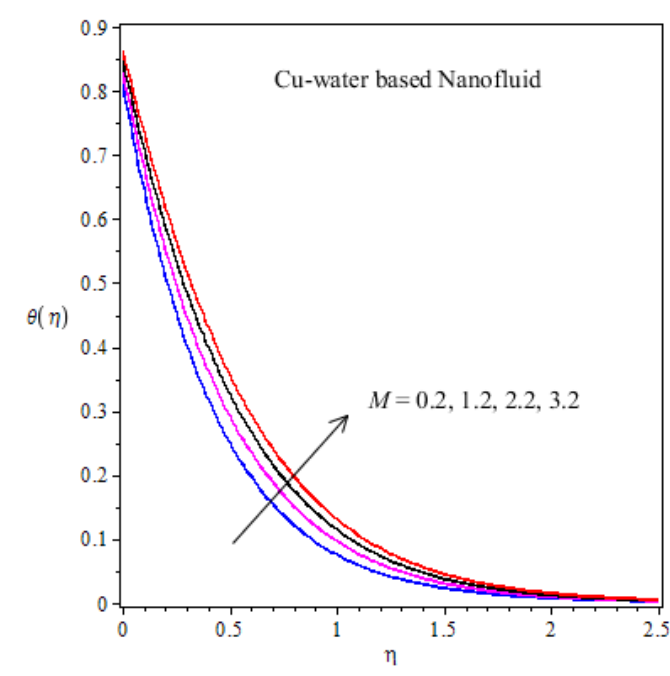

Figure 4b. Temperature profiles variation for varying values of $M$

Figures $6 \mathrm{a}$ and $6 \mathrm{~b}$ quantify the significance of velocity slip factor on the flow field. These figures emphasize that the nanofluid velocity is retarded whereas fluid temperature gets augmented due to velocity slip parameter $\lambda_{3}$. This phenomena 
is due to the reason that in the proximity of sheet both fluid and stretching sheet velocities are not same when slip occurs and as a result the fluid velocity gets diminished with increase in velocity slip factor parameter because in the existence of slip condition pulling of stretching is partially transmitted to fluid, which reveals that the velocity slip has significant impact on the flow of fluid. Figures $7 \mathrm{a}$ and $7 \mathrm{~b}$ inferred the diminishing impact on the profiles of both nanofluid velocity and temperature for suction parameter $S(>0)$ while it has a reversal effect on increasing the injection parameter $S(<0)$. This phenomena is owing to the reason that the momentum boundary layer during suction sticks very close to the stretching sheet, which demolish the flow momentum and as a result nanofluid fluid velocity gets reduced while injection appends fluid by means of lateral mass flux over the sheet which tends to assist the momentum of flow and consequently the fluid velocity gets augmented. Figure 8 demonstrates the thermal radiation effect on the nanofluid temperature. It is clear that the $\mathrm{Cu}$ based nanofluid temperature is enhanced due to rising of thermal radiation parameter because it increases the conduction effect of the fluid and consequently thermal boundary layer turn into thicker. The consequence of viscous dissipation on $\mathrm{Cu}$ based fluid temperature is show in Figure 9. It is noticed that the increasing values of $E c$ leads to enhancement in the fluid temperature. This implies that the viscous dissipation tends to augment the nanofluid temperature in the regime of boundary layer.

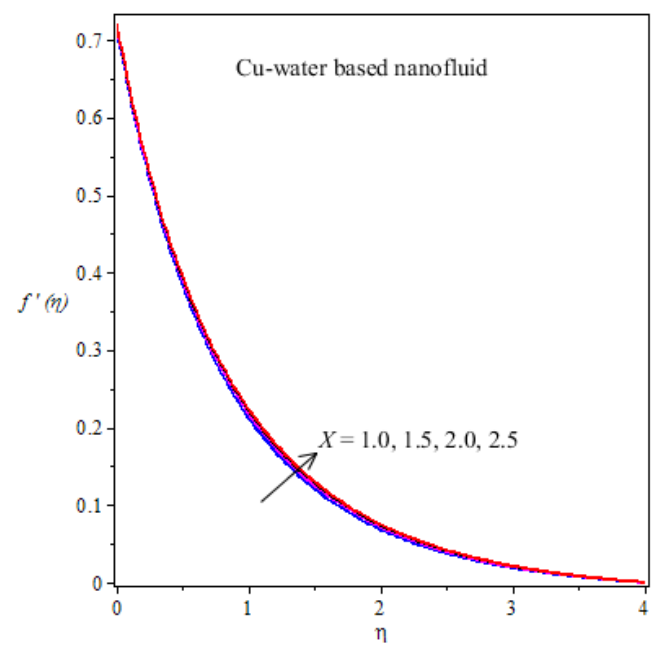

Figure 5a. Velocity profiles variation for varying values of $X$

Figures $10 \mathrm{a}$ and $10 \mathrm{~b}$ exemplify the impacts of $M, \phi$ and $X$ on the wall velocity gradient and local Nusselt number $N u_{x}$. These figures signify that an increase in either $M$ or $\phi$ leads to reduce the skin friction coefficient $\left|C f_{x}\right|$ while it is enhanced due to amplification of dimensionless coordinate $X$. Further, the local Nusselt number $N u_{x}$ gets augmented due to intensification of $M, \phi$ and $X$. Figures $11 \mathrm{a}$ and $11 \mathrm{~b}$ reckon the significance of suction/injection parameter $S$ and velocity slip parameter $\lambda_{3}$ on skin friction coefficient and local Nusselt number. It is interesting to mention that both skin friction coefficient and local Nusselt number in magnitude increase due to enhancement in injection and velocity slip parameters while both decrease on increasing the suction parameter. Physically, it is interoperated that due to injection and velocity slip factor both shear stress and rate of heat transfer get enhanced at the stretched sheet whereas suction has a reversal impact. From Figure 12, it is noticed that the magnitude of local Nusselt number increases due to amplification of Eckert number Ec, radiation parameter $R$ and thermal slip parameter $\delta_{2}$. This implies that viscous dissipation, thermal radiation and thermal slip have propensity to augment the rate of wall temperature gradient over the stretching sheet.

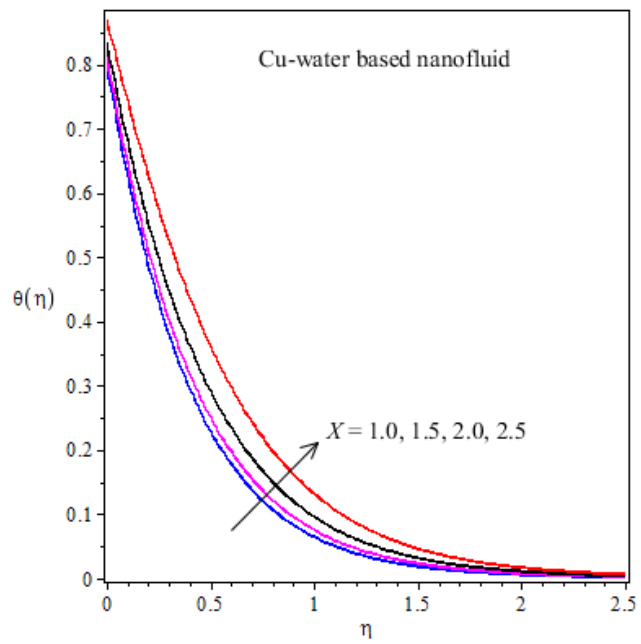

Figure 5b. Temperature profiles variation for varying values of $X$

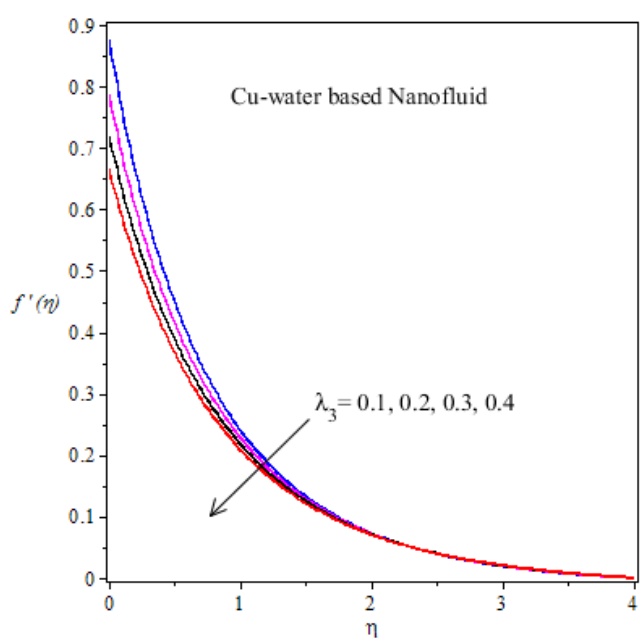

Figure 6a. Velocity profiles variation for varying values of

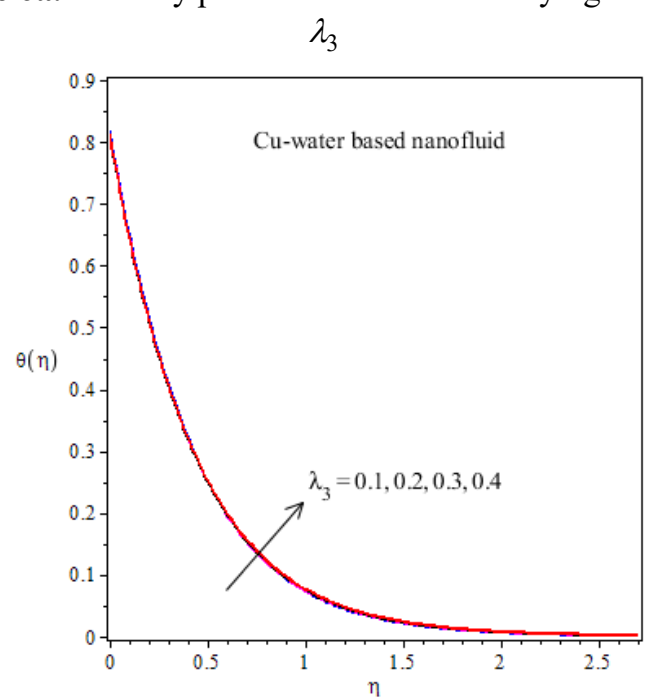

Figure 6b. Temperature profiles variation for varying values of $\lambda_{3}$ 


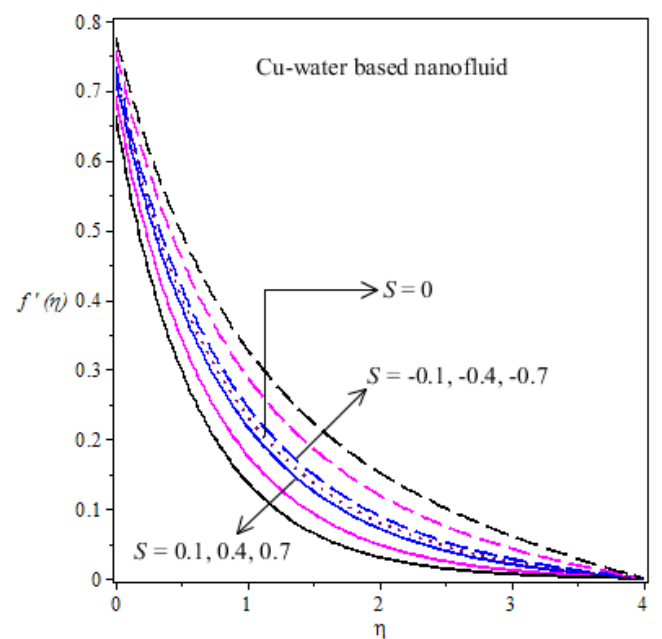

Figure 7a. Velocity profiles variation for varying values of $S$

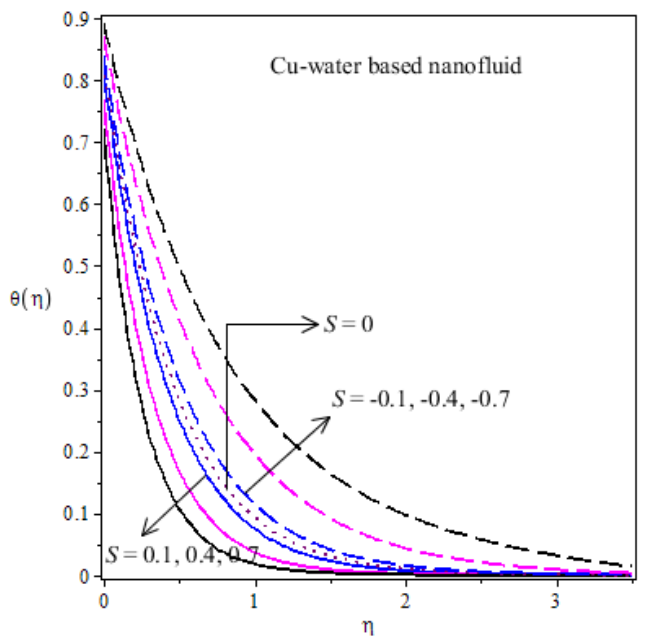

Figure $\mathbf{7 b}$. Temperature profiles variation for varying values of $S$

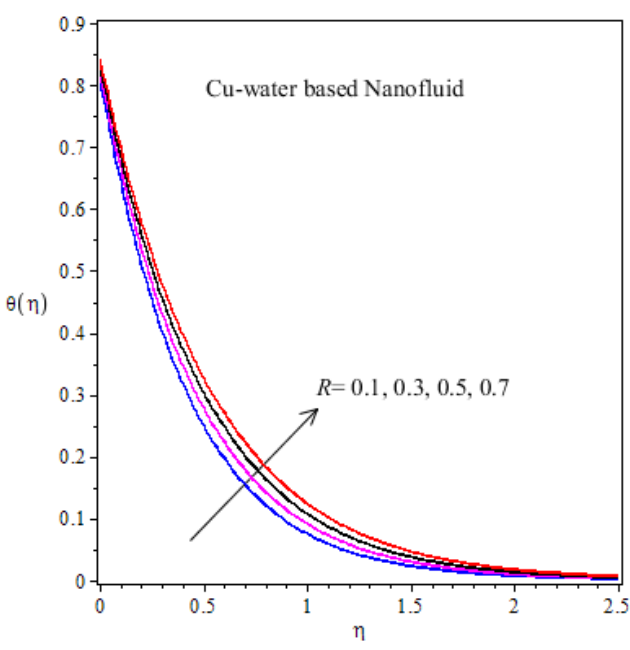

Figure 8. Temperature profiles variation for varying values of $R$

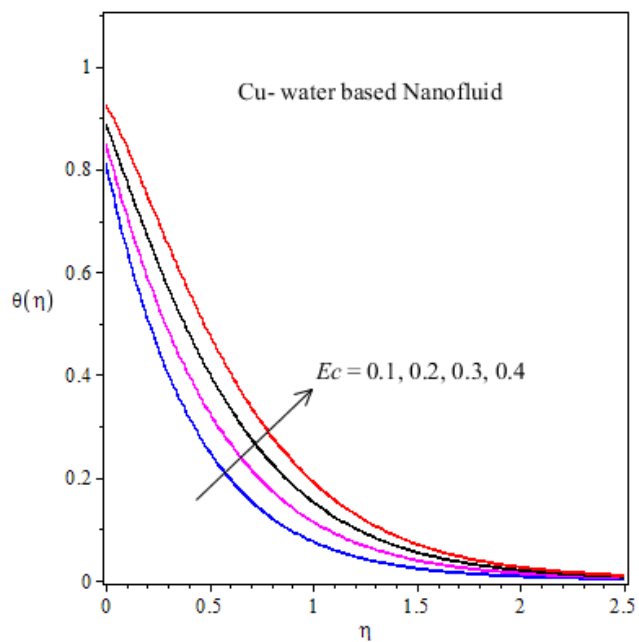

Figure 9. Temperature profiles variation for varying values of $E c$

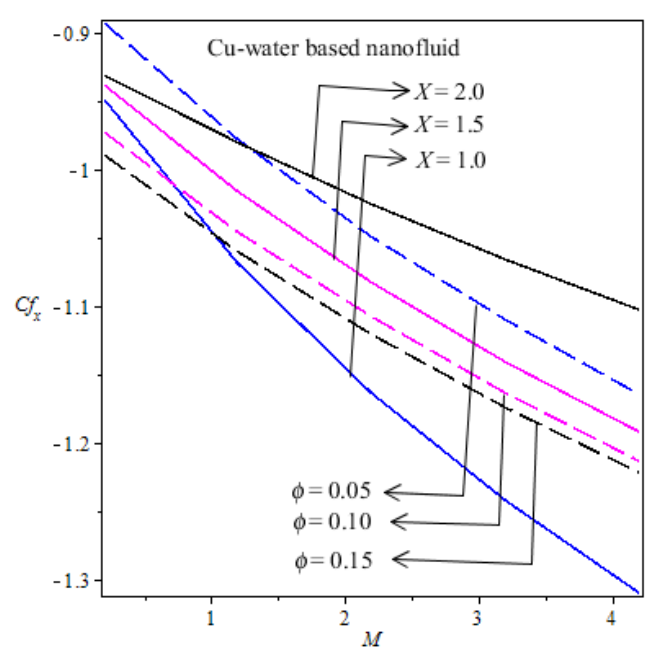

Figure 10a. Profiles of $C f_{x}$ for varying values of $X, \phi$ and $M$

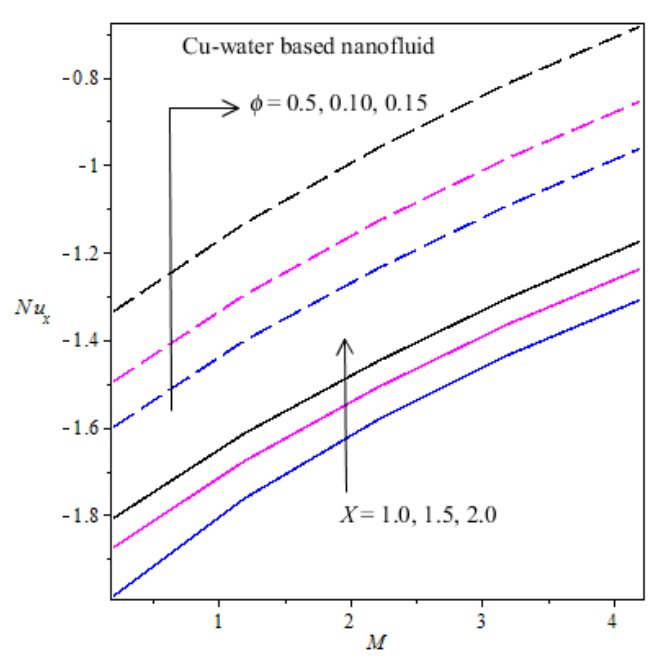

Figure 10b. Profiles of $N u_{x}$ for varying values of $X, \phi$ and $M$ 


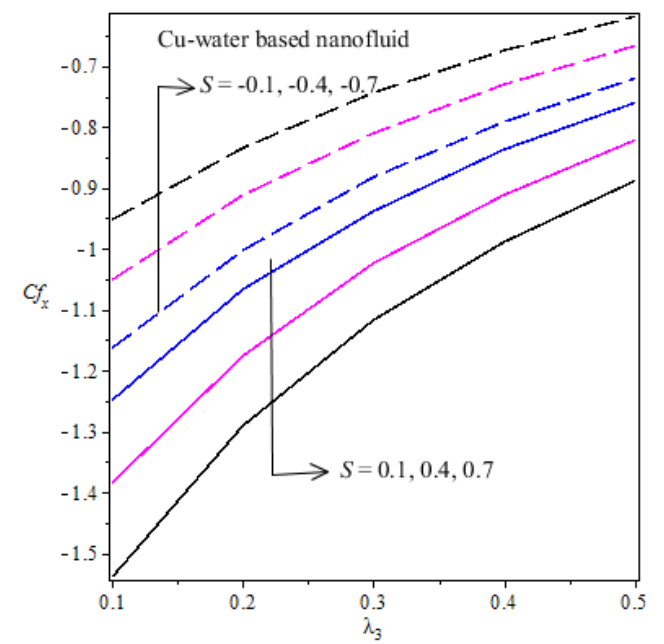

Figure 11a. Profiles of $C f_{x}$ for varying values of $S$ and $\lambda_{3}$

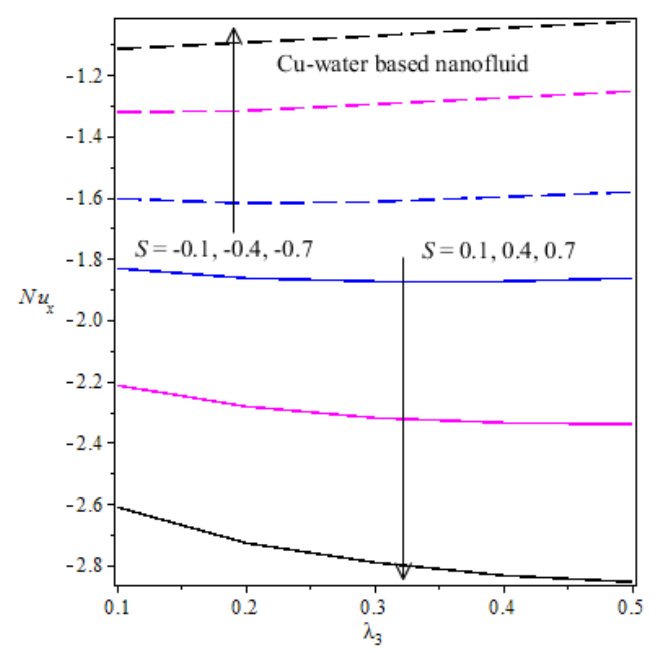

Figure 11b. Profiles of $N u_{x}$ for varying values of $S$ and $\lambda_{3}$

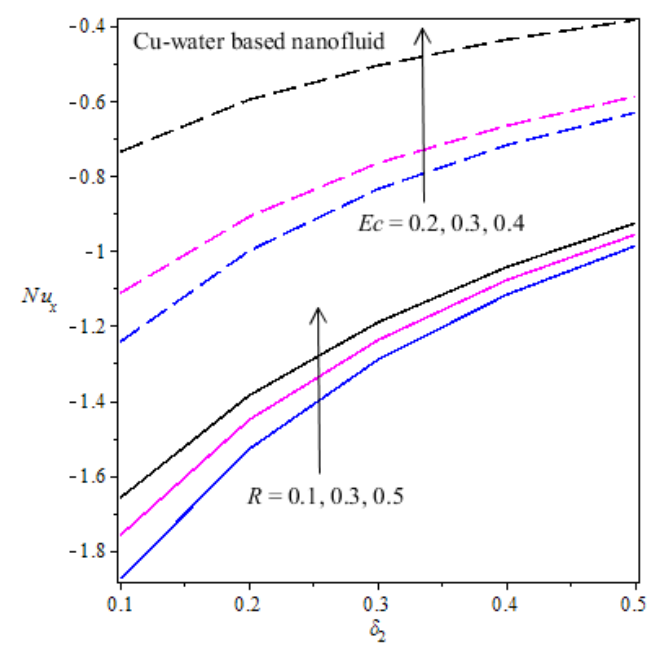

Figure 12. Profiles of $N u_{x}$ for varying values of $E c, R$ and $\delta_{2}$

\section{VALIDATION OFIMPLEMENTED NUMERICAL METHOD}

The accuracy of numerical algorithm implemented in our study has been validated by comparing the numerical values of local Nusselt number $N u_{x}$ with existed limiting results of Rashidi et al. [45] when $X=\delta_{0}=S=\lambda_{3}=\delta_{2}=E c=\xi=$ $0, \phi=0.05, R=0.1$ and $\operatorname{Pr}=6.2$ and Pal [32] when $X=$ $1.5, S=\lambda_{3}=\delta_{2}=R=\phi=0, \delta_{0}=2, E c=0.1, \xi=$

0.1 and $\mathrm{Pr}=6.2$. The comparison of both the results reveals an excellent conformity of present results as it is evident from Table 2, which accentuates the correctness of the implemented numerical algorithm.

Table 2. Comparison of numerical values of $N u_{x}$ i.e. local Nusselt number with the previous results reported by Rashidi et al. [45] and Pal [32]

\begin{tabular}{cccc}
\hline$M$ & $\begin{array}{c}\text { Rashidi et al. } \\
{[45]}\end{array}$ & Pal [32] & Present result \\
\hline $\mathbf{0 . 5}$ & -1.401345 & -1.40134 & -1.401347 \\
\hline $\mathbf{1 . 5}$ & -1.291168 & -1.29116 & -1.291166 \\
\hline $\mathbf{2 . 5}$ & -1.206645 & -1.20664 & -1.206645 \\
\hline $\mathbf{3 . 5}$ & -1.138282 & -1.13828 & -1.138281 \\
\hline
\end{tabular}

\section{QUADRATIC REGRESSION ESTIMATION}

Quadratic regression analysis is one kind of statistical technique for estimating the relationship of the variables. More precisely, regression analysis plays a significant role to comprehend how the particular value of a dependent variable varies due to change of an independent variable keeping other independent variables fixed. In this section, an analysis of quadratic regression estimation for the skin friction coefficient $C f_{x}$ and local Nusselt number $N u_{x}$ has been presented. The estimated numerical values of $C f_{x}$ and $N u_{x}$ have been computed for 125 sets of various values of $S$ and $\lambda_{3}$ taken from the intervals $[0.5,3]$ and $[0.05,0.50]$, respectively, whereas other parameters are considered fixed as mentioned.

The quadratic regression estimated model for $C f_{x}$ and $N u_{x}$ are mentioned below

$$
\begin{aligned}
& C f_{\text {qre }}=C f_{x}+b_{1} S+b_{2} \lambda_{3}+b_{3} S^{2}+b_{4} \lambda_{3}^{2}+b_{5} S \lambda_{3}, \\
& N u_{\text {qre }}=N u_{x}+c_{1} S+c_{2} \lambda_{3}+c_{3} S^{2}+c_{4} \lambda_{3}^{2}+c_{5} S \lambda_{3},
\end{aligned}
$$

where $b_{1}, b_{2}, b_{3}, b_{4}$ and $b_{5}$ are the coefficients skin friction estimations and $c_{1}, c_{2}, c_{3}, c_{4}$ and $c_{5}$ are coefficients of local Nusselt number estimations.

The coefficients of quadratic regression estimation corresponding to skin friction coefficient $C f_{x}$ and local Nusselt number $N u_{x}$ are presented in Tables 3 and 4 for different values of magnetic parameter $M$ and volume fraction of nanoparticle $\phi$.Moreover, the maximum values of relative error bounds $\varepsilon_{1}=\left|C f_{\text {qre }}-C f_{x}\right| / C f_{x}$ and $\varepsilon_{2}=$ $\left|N u_{\text {qre }}-N u_{x}\right| / N u_{x}$ are also computed. These tables indicate that the coefficients of $\lambda_{3}$ are greater as compared to $S$ which reveal that small change in $\lambda_{3}$ leads in a maximum perturbation in both the shear stress and rate of heat transfer at the stretched sheet. This suggests that the velocity slip factor has augmenting impact on both the wall velocity gradient and rate of heat transfer at the stretched sheet. This observation is also justified from Figures $11 \mathrm{a}$ and $11 \mathrm{~b}$. 
Table 3. Estimated quadratic regression coefficients and relative error bounds of $C f_{x}$ for varying $M$ and $\phi$

\begin{tabular}{ccccccccc}
\hline$M$ & $\phi$ & $C f_{x}$ & $\mathrm{~b} 1$ & $\mathrm{~b} 2$ & $\mathrm{~b} 3$ & $\mathrm{~b} 4$ & $\mathrm{~b} 5$ & $\mathcal{E}_{1}$ \\
\hline 0.2 & 0.05 & -1.3959 & -0.5845 & 2.7321 & 0.0014 & -1.9956 & 1.1241 & 0.0202 \\
\hline 0.2 & 0.15 & -1.5060 & -0.6970 & 3.1769 & 0.0087 & -2.3746 & 1.3743 & 0.0229 \\
\hline 2.2 & 0.05 & -1.6721 & -0.5630 & 3.3107 & 0.0083 & -2.5384 & 1.1014 & 0.0157 \\
\hline 2.2 & 0.15 & -1.7632 & -0.6704 & 3.7293 & 0.0145 & -2.9066 & 1.3417 & 0.0183 \\
\hline
\end{tabular}

Table 4. Estimated quadratic regression coefficients and relative error bounds of $N u_{x}$ for varying $M$ and $\phi$

\begin{tabular}{ccccccccc}
\hline$M$ & $\phi$ & $N u_{x}$ & $\mathrm{c} 1$ & $\mathrm{c} 2$ & $\mathrm{c} 3$ & $\mathrm{c} 4$ & $\mathrm{c5}$ & $\varepsilon_{2}$ \\
\hline 0.2 & 0.05 & 1.6716 & 1.3010 & 0.8284 & -0.0426 & -0.5380 & 0.9506 & 0.0188 \\
\hline 0.2 & 0.15 & 1.2171 & 0.8133 & 1.4702 & 0.0655 & -1.2130 & 1.1356 & 0.0299 \\
\hline 2.2 & 0.05 & 1.1032 & 1.5575 & 1.9188 & -0.0551 & -0.9994 & 0.9473 & 0.0500 \\
\hline 2.2 & 0.15 & 0.6162 & 1.0985 & 2.7008 & 0.0456 & -1.8575 & 1.0880 & 0.1049 \\
\hline
\end{tabular}

\section{CONCLUSIONS}

In this study, we have examined the impact of thermal radiation on viscous dissipative boundary layer flow of heat absorbing magneto-nanofluid over a permeable exponentially stretching sheet considering Navier's velocity and thermal slips into account. Three kinds of water based nanofluids having alumina $\left(\mathrm{Al}_{2} \mathrm{O}_{3}\right)$, copper $(\mathrm{Cu})$ and titanium oxide $\left(\mathrm{TiO}_{2}\right)$ as nanoparticles are chosen for this investigation. Numerical computations are performed for various physical parameters and their significance on the flow field is quantified through numerous graphs. The quadratic regression analysis on the numerical data of $C f_{x}$ and $N u_{x}$ has been presented to verify the relationship among the controlling physical parameters and transfer rate parameters. The implemented numerical algorithm has been validated by comparing the numerical values of $N u_{x}$ with existed limiting results considering special assumptions. Following significant findings are drawn from various figures and tables:

(i) The velocity and temperature distribution profiles are lower for $\mathrm{Cu}$-water nanofluid followed by $\mathrm{Al}_{2} \mathrm{O}_{3}$ and $\mathrm{TiO}_{2}$ water base nanofluids in the regime of boundary layer.

(ii) The volume fractions of nanoparticle, exerted magnetic field and velocity slip factor have diminishing impact on the velocity and augmenting impact on the temperature profiles for $\mathrm{Cu}$-water nanofluid.

(iii) Both the $\mathrm{Cu}$-water fluid velocity and temperature are increased due to injection parameter where suction parameter has reversal impact.

(iv) The viscous dissipation and thermal radiation have tendency to augment the $\mathrm{Cu}$-water temperature over the stretching sheet.

(v) In case of $\mathrm{Cu}$ based nanofluid, the shear stress at the stretching sheet is reduced whereas rate of heat transfer is enhanced due to amplification of magnetic parameter, volume fraction of nanoparticle.

(vi) Viscous dissipation, thermal slip factor and thermal radiation have propensity to augment the heat transfer rate over the stretched sheet for $\mathrm{Cu}$-water nanofluid.

\section{REFERENCES}

[1] Choi SUS. (1995). Enhancing thermal conductivity of fluids with nanoparticles, developments and applications of non-Newtonian flows. ASME FED 231/MD 66: 99-105.

[2] Buongiorno J. (2006). Convective transport in nanofluids. ASME Journal of Heat Transfer 128: 240250. https://doi.org/10.1115/1.2150834

[3] Jang SP, Choi SUS. (2007). Effects of various parameters on nanofluid thermal conductivity. ASME Journal of Heat Transfer 129: 617-623. https://doi.org/10.1115/1.2712475

[4] Azimi SS, Kalbasi M. (2014). Numerical study of dynamic thermal conductivity of nanofluid in the forced convective heat transfer. Applied Mathematical Modelling 38(4): 1373-1384. https://doi.org/10.1016/j.apm.2013.08.027

[5] Hassan H, Harmand S. (2015). Effect of using nanofluids on the performance of rotating heat pipe. Applied Mathematical Modelling 39: 4445-4462. https://doi.org/10.1016/j.apm.2014.12.023

[6] Garoosi F, Rohani B, Rashidi MM. (2015). Two-phase mixture modeling of mixed convection of nanofluids in a square cavity with internal and external heating. Powder Technology 275: 304-321. https://doi.org/10.1016/j.powtec.2015.02.015

[7] Arefmanesh A, Aghaei A, Ehteram H. (2016). Mixed convection heat transfer in a $\mathrm{CuO}$-water filled trapezoidal enclosure, effects of various constant and variable properties of the nanofluid. Applied Mathematical Modelling 40: 815-831. https://doi.org/10.1016/j.apm.2015.10.043

[8] Pan M, Zheng L, Liu F, Zhang X. (2016). Modeling heat transport in nanofluids with stagnation point flow using fractional calculus. Applied Mathematical Modelling 40: 8974-8984. https://doi.org/10.1016/j.apm.2016.05.044

[9] Ellahi R, Hassan M, Zeeshan A. (2016). Aggregation effects on water base $\mathrm{Al}_{2} \mathrm{O}_{3}$ nano fluid over permeable wedge in mixed convection. Asia-Pacific Journal of Chemical Engineering 11: 179-186. https://doi.org/10.1002/apj.1954

[10] Ellahi R, Zeeshan A, Hassan M. (2016). Particle shape effects on Marangoni convection boundary layer flow of a nanofluid. International Journal of Numerical Methods for Heat and Fluid Flow 26: 2160-2174. https://doi.org/10.1108/HFF-11-2014-0348

[11] Malvandi A, Ganji DD. (2014). Effects of nanoparticle migration on force convection of alumina/water 
nanofluid in a cooled parallel-plate channel. Advanced Powder Technology 25: 1369-1375. https://doi.org/10.1016/j.apt.2014.03.017

[12] Malvandi A, Ganji DD. (2016). Mixed convection of alumina-water nanofluid inside a concentric annulus considering nanoparticle migration. Particuology 24: 113-122. https://doi.org/10.1016/j.partic.2014.12.017

[13] Pavlov KB. (1974). Magnetohydrodynamic flow of an incompressible fluid caused by deformation of a plane surface. Magnetohydrodynamics 10: 507-510.

[14] Chakrabarti A, Gupta AS. (1979). Hydromagnetic flow and heat transfer over a stretching sheet. Quarterly of Applied Mathematics 37(1): 73-78.

[15] Makinde OD, Khan WA, Khan ZH. (2013). Buoyancy effects on MHD stagnation point flow and heat transfer of a nanofluid past a convectively heated stretching/shrinking sheet. International Journal of Heat and Mass Transfer 62: 526-533. https://doi.org/10.1016/j.ijheatmasstransfer.2013.03.049

[16] Hayat T, Shehzad SA, Alsaedi A. (2014). MHD three dimensional flow by an exponentially stretching surface with convective boundary condition. Journal of Aerospace $\quad$ Engineering 27(4): 1-8. https://doi.org/10.1061/(ASCE)AS.1943-525.0000360

[17] Khan Y. (2017). Magnetohydrodynamic flow of linear visco-elastic fluid model above a shrinking/stretching sheet: A series solution. Scientia Iranica B 24(5): 24662472.

[18] Elbashbeshy EMA. (2001). Heat transfer over an exponentially stretching continuous surface with suction. Archives of Mechanics 53(6): 643-651.

[19] Elbashbeshy EMA, Bazid MAA. (2003). Heat transfer over an unsteady stretching surface with internal heat generation. Applied Mathematics and Computation 138(2-3): 239-245. https://doi.org/10.1016/S00963003(02)00106-6

[20] Ibrahim SM, Mabood F, Kumar PV, Lorenzini G, Lorenzini E. (2018). Cattaneo-Christov heat flux on UCM flow across a melting surface with cross diffusion and double stratification. Italian Journal of Engineering Science: Tecnica Italiana 61+1(1): 12-21. https://doi.org/ 10.18280/ijes.620102

[21] Makinde OD, Khan WA, Culham, JR. (2016). MHD variable viscosity reacting flow over a convectively heated plate in a porous medium with thermophoresis and radiative heat transfer. International Journal of Heat and Mass Transfer 93: 595-604. https://doi.org/10.1016/j.ijheatmasstransfer.2015.10.050

[22] Makinde OD, Mabood F, Khan WA, Tshehla MS. (2016). MHD flow of a variable viscosity nanofluid over a radially stretching convective surface with radiative heat. Journal of Molecular Liquids 219: 624630. https://doi.org/10.1016/j.molliq.2016.03.078

[23] Makinde OD, Animasaun IL. (2016). Bioconvection in MHD nanofluid flow with nonlinear thermal radiation and quartic autocatalysis chemical reaction past an upper surface of a paraboloid of revolution. International Journal of Thermal Sciences 109: 159171. https://doi.org/10.1016/j.ijthermalsci.2016.06.003

[24] Makinde OD. (2012). Chemically reacting hydromagnetic unsteady flow of a radiating fluid past a vertical plate with constant heat flux. Zeitschriftfür $\begin{array}{llll}\text { Naturforschung } & \text { A } & \text { 67(5): }\end{array}$ https://doi.org/10.5560/zna.2012-0014
[25] Makinde OD. (2012). Heat and mass transfer by MHD mixed convection stagnation point flow toward a vertical plate embedded in a highly porous medium with radiation and internal heat generation. Meccanica 47(5): 1173-1184. https://doi.org/10.1007/s1 1012-011-9502-5

[26] Ali N, Khan SU, Abbas Z, Sazid M. (2017). Soret and Dufour effects on hydromagnetic flow of viscoelastic fluid over porous oscillatory stretching sheet with thermal radiation. Journal of the Brazilian Society of Mechanical Sciences and Engineering 38: 2533-2546. https://doi.org/10.1007/s40430-016-0506-x

[27] Vajravelu K, Hadjinicolaou A. (1993). Heat transfer in a viscous fluid over a stretching sheet with viscous dissipation and internal heat generation. International Communications in Heat and Mass Transfer 20(3): 417430. https://doi.org/10.1016/0735-1933(93)90026-R

[28] Partha MK, Murthy PVSN, Rajasekhar GP. (2005). Effect of viscous dissipation on the mixed convection heat transfer from an exponentially stretching surface. Heat and Mass Transfer 41(4): 360-366. https://doi.org/10.1007/s00231-004-0552-2

[29] Cortell R. (2008). Effect of viscous dissipation and radiation on the thermal boundary layer over a nonlinearly stretching sheet. Physics Letters A 372(5): 631636. https://doi.org/10.1016/j.physleta.2007.08.005

[30] Aziz EMA. (2009). Viscous dissipation effect on mixed convection flow of a micropolar fluid over an exponentially stretching sheet. Canadian Journal of Physics 87(4): 359-368. https://doi.org/10.1139/P09047

[31] Anjali Devi SP, Ganga B. (2009). Effects of viscous and Joules dissipation on MHD flow, heat and mass transfer past a stretching porous surface embedded in a porous medium. Nonlinear Analysis: Modelling and Control 14(3): 303-314.

[32] Pal D. (2010). Mixed convection heat transfer in the boundary layers on an exponentially stretching surface with magnetic field. Applied Mathematics and Computation 217(6): 2356-2369. https://doi.org/10.1016/j.amc.2010.07.035

[33] Seth GS, Singh JK. (2016). Mixed convection hydromagnetic flow in a rotating channel with hall and wall conductance effects. Applied Mathematical Modelling 40: 2783-2803. https://doi.org/10.1016/j.apm.2015.10.015

[34] Seth GS, Sarkar S, Makinde OD. (2016). Combined free and forced convection Couette-Hartmann flow in a rotating channel with arbitrary conducting walls and Hall effects. Journal of Mechanics 32(5): 613-629. https://doi.org/10.1017/jmech.2016.70

[35] Seth GS, Sharma R, Mishra MK, Chamkha AJ. (2017). Analysis of hydromagnetic natural convection radiative flow of a visco-elastic nanofluid over a stretching sheet with Soret and Dufour effects. Engineering Computation 34: 603-628. https://doi.org/10.1108/EC10-2015-0290

[36] Seth GS, Tripathi R, Mishra MK. (2017). Hydromagnetic thin film flow of Casson fluid in nonDarcy porous medium with Joule dissipation and Navier's partial slip. Applied Mathematics and Mechanics 38(11): 1613-1626. https://doi.org/10.1007/s10483-017-2272-7

[37] Mukhopadhyay S, Gorla RSR. (2012). Effects of partial slip on boundary layer flow past a permeable 
exponential stretching sheet in presence of thermal radiation. Heat and Mass Transfer 48(10): 1773-1781. https://doi.org/10.1007/s00231-012-1024-8

[38] Mukhopadhyay S. (2013). Slip effects on MHD boundary layer flow over an exponentially stretching sheet with suction/blowing and thermal radiation. Ain Shams Engineering Journal 4(3): 485-491. https://doi.org/10.1016/j.asej.2012.10.007

[39] Sharma R, Ishak A, Nazar R, Pop I. (2014). Boundary layer flow and heat transfer over a permeable exponentially shrinking sheet in the presence of thermal radiation and partial slip. Journal of Applied Fluid Mechanics $7(1)$ : 125-134. https://doi.org/10.18869/acadpub.jafm.68.235.24834

[40] Oztop HF, Abu-Nada E. (2008). Numerical study of natural convection in partially heated rectangular enclosures filled with nanofluids. International Journal of Heat and Fluid Flow 29(5): 1326-1336. https://doi.org/10.1016/j.ijheatfluidflow.2008.04.009

[41] Khalid A, Khan I, Shafie S. (2015). Exact solutions for free convection flow of nanofluids with ramped wall temperature. The European Physical Journal Plus 130: 57. https://doi.org/10.1140/epjp/i2015-15057-9

[42] Das S, Jana RN, Makinde OD. (2016). Magnetohydrodynamic free convective flow of nanofluids past an oscillating porous flat plate in a rotating system with thermal radiation and Hall effects. Journal Mechanics 32(2): 197-210. https://doi.org/10.1017/jmech.2015.49

[43] Siegel R, Howell JR. (1993). Thermal radiation heat transfer [3rd ed]. McGraw-Hill Series in Transportation, pp. 748-751.

[44] Pal D, Mandal G, Vajravalu K. (2016). Soret and Dufour effects on MHD convective-radiative heat and mass transfer of nanofluids over a vertical non-linear stretching/shrinking sheet. Applied Mathematics and Computation 287-288: 184-200. https://doi.org/10.1016/j.amc.2016.04.037

[45] Rashidi MM, Vishnu Ganesh N, Abdul Hakeem AK, Ganga B. (2014). Buoyancy effect on MHD flow of nanofluid over a stretching sheet in the presence of thermal radiation. Journal of Molecular Liquids 198: 234-238. https://doi.org/10.1016/j.molliq.2014.06.037

\section{NOMENCLATURE}

Ec Eckert number

$k^{*} \quad$ Rosseland mean absorption coefficient

$k_{n f} \quad$ Thermal conductivity of nanofluid

$M \quad$ Magnetic parameter

Pr Prandtl number

$q_{r} \quad$ Radiative heat flux

$R \quad$ Radiation parameter

Re Reynold's number

$S \quad$ Suction / injection parameter

$\bar{T} \quad$ Temperature of nanofluid

$\bar{u} \quad$ Nanofluid velocity along $\mathrm{x}$-axis

$\bar{v} \quad$ Nanofluid velocity along $\mathrm{y}$-axis

\section{Greek symbols}

$\delta_{2} \quad$ Thermal slip parameter

$\lambda_{3} \quad$ Velocity slip parameter

$\mu_{f} \quad$ Base fluid dynamic viscosity

$\mu_{n f} \quad$ Dynamics viscosity of nanofluid

$\xi \quad$ Heat absorption parameter

$\rho_{f} \quad$ Base fluid density

$\rho_{n f} \quad$ Nanofluid density

$\rho_{s} \quad$ Nanofluid density

$\left(\rho c_{p}\right)_{f}$ Base fluid's heat capicitance

$\left(\rho c_{p}\right)_{n f}$ Heat capacitance of nanofluid

$\left(\rho c_{p}\right)_{s}$ Heat capicitance of nanoparticles

$\sigma^{*} \quad$ Stefan Boltzmann constant

$\sigma_{f} \quad$ Base fluid electrical conductivity

$\sigma_{n f} \quad$ Nanofluid electrical conductivity

$\sigma_{s} \quad$ Nanofluid electrical conductivity

$\phi \quad$ Volume fraction of nanoparticles 